\title{
Big Data, Big Change: In the Financial Management
}

\author{
Ming Ke, Yuxin Shi \\ Beijing Wuzi University, Beijing, China \\ Email: keming2012@sina.com, shiyuxin0604@163.com
}

Received 7 July 2014; revised 13 August 2014; accepted 26 August 2014

Copyright (C) 2014 by authors and Scientific Research Publishing Inc.

This work is licensed under the Creative Commons Attribution International License (CC BY). http://creativecommons.org/licenses/by/4.0/

(c) (i) Open Access

\begin{abstract}
In recent years, "Big Data" has attracted increasing attention. It has already proved its importance and value in several areas, such as aerospace research, biomedicine, and so on. In "Big Data" era, financial work which is dominated by transaction, business record, business accounting and predictions may spring to life. This paper makes an analysis about what change that "Big Data" brings to Accounting Data Processing, Comprehensive Budget Management, and Management Accounting through affecting the idea, function, mode, and method of financial management. Then the paper states the challenges that "Big Data" brings to enterprise aiming to illustrate that only through fostering strengths and circumventing weaknesses can an enterprise remain invincible in "Big Data" era.
\end{abstract}

\section{Keywords}

Big Data, Financial Management, Change, Challenge

\section{Introduction to Big Data}

In recent years, "Big Data” has been increasingly mentioned. It is used to describe and define reams of data generated in information explosion era. As a column in the New York Times in February, 2012 reported, "Big Data” era has arrived. In the field of business, economy and otherwise, it is data and analysis not experience and intuition that are the bases of decision-making. In "Big Data" era, financial work which is dominated by transaction, business record, business accounting and predictions may spring to life. The idea, function, mode and method of financial management will make a subversive change.

Though there has been an increasing emphasis on big data in recent years, the definition of “Big Data” hasn’t reached a consensus. Gartner which is an authority IT research and consulting firm defines that as follows: "Big Data is high-volume, high-velocity, and/or high variety information assets that require new forms of processing 
to enable enhanced decision making, insight discovery and process optimization [1].” IBM says: "Big Data is being generated by everything around us at all times. Every digital process and social media exchange produces it. Systems, sensors and mobile devices transmit it. Big Data is arriving from multiple sources at an alarming velocity, volume and variety [2]." The National Science Foundation (NSF) defines Big Data as "scientific instruments, sensors, Internet, E-mail, audio and video software, network click stream data sources generate a variety of large-scale, diversified, complicated and long-term distributed data set” [3].

Anyhow, the characteristics of Big Data are usually reduced to 4 Vs (Figure 1):

1) Volume. The data unit has developed from GB, TB to PB, EB, ZB, even YB. And 1YB = 1024ZB, $1 \mathrm{ZB}=$ 1024EB, 1EB = 1024PB, 1PB = 1024TB, 1TB = 1024GB.

2) Velocity. Big data's speed of updating and changing is surprising. The enterprise has to process the mass data generated from or coming into business continuously at short notice. Only in this way can the Big Data's business value be maximized.

3) Variety. It has a variety of data types besides structured data, such as text, voice, graph, video, click stream and so on.

4) Value. Data are useful. It enables enterprise to find and come up with some new problems. IBM reduces the $4^{\text {th }} \mathrm{V}$ to Veracity for the reason that only real and accurate data can make the control on data meaningful.

Big Data is also a wrapper for different types of granular data. The five key sources of Big Data are public data, private data, data exhaust, community data, and self-quantification data. "Public data" are data typically held by governments, governmental organizations, and local communities that can potentially be harnessed for wide- ranging business and management applications. "Private data" are data held by private firms, non-profit organizations, and individuals that reflect private information that cannot readily be imputed from public sources. "Data exhaust" refers to ambient data that are passively collected, non-core data with limited or zero value to the original data-collection partner. "Community data" are a distillation of unstructured data—especially text—into dynamic networks that capture social trends. "Self-quantification data" are types of data that are revealed by the individual through quantifying personal actions and behaviors [4].

Big Data has already proved its importance and value in several areas. Organizations such as the National Oceanic and Atmospheric Administration (NOAA), the National Aeronautics and Space Administration (NASA), several pharmaceutical companies, and numerous energy companies have amassed huge amounts of data and now leverage big data technologies on a daily basis to extract value from them [5]. In fact, Big Data should attract financial personnel's and managers' attention in all industries so as to improve the core competitiveness of enterprises.

\section{Big Data, Big Change: Accounting Data Processing}

As the core of an enterprise, accounting data reflects and supports the normal running of business and capital. Through processing accounting data and mining financial information fully, the enterprise could improve its financial management, lower cost of capital, and make fat profit.

\subsection{The Development History of Accounting Data Processing}

Accounting Data is the record of all kinds of economic affairs occurring in business operation. It's the origin of

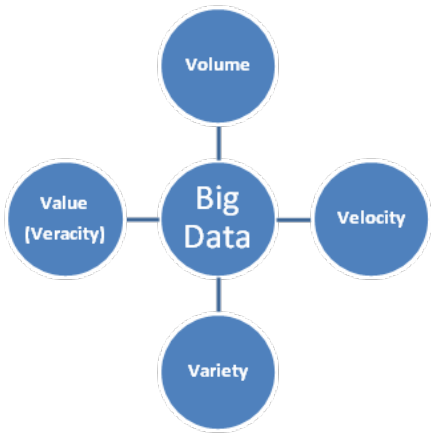

Figure 1. The characteristics of big data (4 Vs) 
financial information. Processing accounting data is gathering, storing, machining, transferring, and analyzing accounting data. Up to now, the development history of accounting data processing can be divided into five stages (Table 1):

- Manual Process: In this stage, accountants regard their eyes, ears as input unit, record economic affairs with pens and paper, store them, cure them, then transfer them. Manual process has two main advantages: One is flexibility. It's easy to adjust when the processing mode and program of accounting affairs change. The other is reliability. Accounting affairs will not suspend completely just because of electricity or temperature. Nevertheless, the disadvantages of manual process are obvious, such as low speed, poor efficiency, and high error rate.

- Mechanical Process: In the end of the nineteenth century and at the beginning of the twentieth, industrial economy developed, enterprise scale expanded, and accountants' workload increased. In this case, the mechanical process emerged. Accountants use puncher, verifier, and electronic equipment to gather, store, cure, and transfer accounting data. Compared with manual process stage, mechanical process increases the speed and accuracy of processing. Nevertheless, the equipment is too huge and heavy. It's difficult to operate. And its cost is very high.

- Electronic Computer Process: Electronic computer is composed of input, storage, arithmetic, logic operation, control and output. Centralized storage and automatic processing raise the efficiency of accounting data processing, and increase the timeliness and accuracy of accounting information. In this stage, however, information is shared and exchanged mainly via optical disk and floppy disk. Business accounting and operation procedure just simulate that in manual process stage. There is no relationship among accounting procedures.

- Networked Process: With the network technique developing, financial department can use computers and network to process accounting data, such as intranet, extranet, and internet. Modern Information Technology, especially the ERP system, carries out the integration of business process and accounting procedures, business accounting and accounting management, financial information and non-financial information. It improves the sharing of the enterprise information vastly. In this stage, the data type is just structured data.

- Big Data Process: With the Internet of Things developing and Cloud Computing maturing, Big Data era is coming. In this stage, accounting data connotation is richer and the structure is more complex. The analytical method is more intelligent and the analysis and application become the keys. It's worth noting that once the accounting data is stolen, its damage is greater.

\subsection{Accounting Data Processing in Big Data Era}

With the Information Technology-especially the Internet of Things and the Cloud Computing technology-developing, business accounting has to gather and process high volume and different structure data. Compared with general big data, accounting big data possess the characteristic of "parasitism" besides the 4 Vs. That is to say, accounting data is parasitic on the business data. It doesn't exist breaking away from business data.

Accounting data in Big Data era possess the characteristics of volume, velocity, variety, value, and parasitism. Therefore, accounting data processing is more complex. It needs more than one solution fusing a lot of traditional and modern technologies. Until now, IBM, INTEL, HP, SAP, Oracle, and EMC possess their respective big data solutions [6]. It's worth noting that data is not only asset but also rubbish. Only through integrating (assembling multiple data), selecting (extracting relative data), cleaning (deleting conflicting data), transforming (turning into forms easy to mine), mining (extracting data mode in intelligent means), and estimating (evaluating its value) can make accounting data into asset and useful information [7].

Table 1. The advantages and disadvantages of five stages of accounting data processing.

\begin{tabular}{ccc}
\hline Five Stages & Advantages & Disadvantages \\
\hline Manual Process & Flexibility, Reliability & Low speed, Poor efficiency, High error rate \\
Mechanical Process & Faster speed, Higher accuracy & Heaviness, High cost, Difficult operation \\
Electronic Computer Process & Higher efficiency, Timeliness, Higher accuracy & Independence, Simulation of manual process \\
Networked Process & Integration & Structured data only \\
Big Data Process & Intelligence & Greater damage once being stolen \\
\hline
\end{tabular}




\section{Big Data, Big Change: Comprehensive Budget Management}

Nowadays, enterprise budget management is facing two challenges: One is enterprise is improving its management level. The other is the requirements put forward by supervision department.

First of all, modern enterprise hasn't been satisfied with management after the event making use of ERP software. More and more enterprises expect control in advance. Secondly, with increasing competition, it's more important to make adequate business operation objectives and achieve them. Thirdly, recurrent merger and acquisition makes the management level in Group Company ragged. Therefore, the Group Company requires improving management level urgently. In addition, large-scale Group Company's industry distribution is complex and geographical distribution is scattered. So it requires allocating resources reasonably.

When it comes to budgeting, Lukka pointed out, budget control is found to be difficult due to the fact that adequate and correct budgets are difficult to make and that organizations therefore operate under budget slack [8]. At present, most enterprises are still in primary stage. It's difficult for managers to judge the authenticity and rationality of data, because plenty of data are surmised by experience. Budgeters rarely make budget referring to previous data and future market prospect. And rare enterprise carries out reasonable budget adjustment and rolling forecast. Budget control lacks integrated control system. It depends on managers to examine after the event, without systematic information-based means. In the process of budget analysis, most enterprises are still conducting simple chart analysis. They lack effective access control and don't analyze data aiming at different management objectives.

In Big Data era, structuring a budget information management platform can solve three core problems in comprehensive budget management: How to make scientific management objectives? How to decompose objectives scientifically? How to achieve managers' objectives through performing and analyzing budget?

Take IBM TM1 as an example, it can import all of historical business data into TM1 system. Based on these data, it can conduct multidimensional analysis, compare them with previous data, and then make next period budget. In the meanwhile, TM1 can build models and analyze, decompose, and deliver objectives scientifically based on managers' objectives. More specifically, after acquiring actual data, budgeters accomplish the budget enforcement report through comparing budget data and actual data. Managers can adjust next period strategy and make next period management objectives based on the budget enforcement report. At the same time, we consider that budgeting is not the task of financial department but the entire personnel. All of the departments should participate in the process of making, controlling, and analyzing budget. Sales budget generates cost budget, human resource planning, purchase plan, period charge plan, financing plan, and then accomplish the budget information in profit statement. Thus, budgeters can provide a set of budget report. Under the concerted effort of business departments and financial department, enterprise's limited resources can be distributed to different area, different branches, and different departments. Nevertheless, the budget enforcement control requires being put in the business information system. Because business information system is running at every moment, while budget system runs only in budgeting period, budget adjustment period, and budget analysis period. Thus, under the integration of budget system and business information system, strategic planning, strategic target decomposition, budget making, budget enforcement control, budget analysis report, budget evaluation, and the effect on next period can form a closed loop (Figure 2) [9].

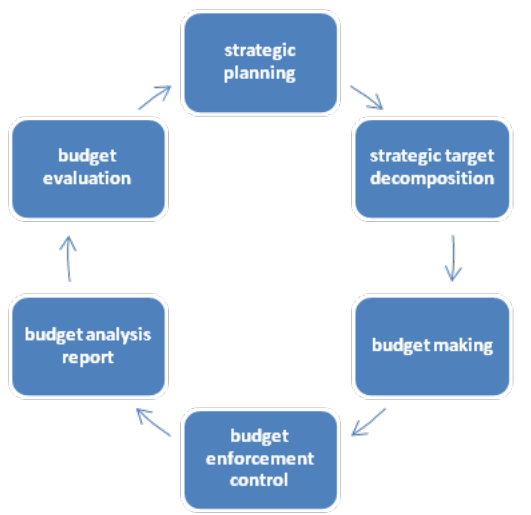

Figure 2. Comprehensive budget management. 


\section{Big Data, Big Change: Management Accounting}

Big Data era’s coming makes management accounting change a lot.

\subsection{Changing from Analyzing Based on Result to Mining Based on Process}

Taking the selling operation analysis in FMCG (Fast-Moving Consumer Goods) industry for example, traditional analysis means is conducting multidimensional analysis based on statistical data generated from terminals, including products, channels, quantity, and sum. The question is when it requires tracing to the source, what we can do is to make a qualitative judgment roughly. That means risk of decision making.

If we extend the data antenna to the terminals facing to consumers, what will happen? For example, when customers come to buy our products, the salespersons can communicate with them passionately. They can ask them the evaluation to products, and how often they come. Even though some customers choose the products of competitors, we still can ask them the reason. For convenience's sake, the salespersons can do it in the way of live recording, and then deliver it to the company background. Thus, it can reduce the salespersons' workload and make sure the authenticity of information. In this process, we obtain structured data like sales volume, unstructured data like consumer's evaluation, and some information about competitors' sales promotion and promotion price. All of information will become enterprise's wealth of great value in Big Data era and turn into income in due time.

\subsection{Changing from Single-Type Data to Multi-Type Data}

In recent years, unstructured data rise rapidly. Through analyzing unstructured data besides structured data, we can conduct financial analysis more comprehensively.

For instance, when an enterprise requires making evaluation on client credit, it isn't confined to financial statement, business background, or status of development. The evaluators can collect information such as positive comment, negative comment on the client from relative website, which enriches our information and reduces information asymmetry in trade.

Considering risk management and control, it is unreliable to estimate the state of operation of one client enterprise just depending on its financial statement. It requires collecting multi-channel information. In $2007 \mathrm{Li}$ Keqiang who is China's prime minister didn’t pay much heed to the figures Liaoning provincial officials feed him, where he was the party chief. He preferred to track Liaoning's economy by looking at other indicators: the cargo volume on the province's railways, electricity consumption and loans disbursed by banks. In Mr Li's honor, The Economist has created a "Keqiang index" for China's economy, combining his three preferred indicators [10].

\subsection{Changing from Periodical Report to Real-Time Report}

With the big data technology developing, the change from periodical financial report to real-time financial report will come true. For example, when the information gathered from terminals changes, personalized marketing strategy and regionalized marketing analysis report can be issued regularly. Even though it's difficult to do it every day, it will come true that doing it every week in the near future.

\section{Big Data, Big Challenge}

Big Data can bring cost saving, risk control, improvement of management efficiency, and increment of value into enterprise. In the meanwhile, Big Data brings some challenges:

\subsection{Unevenness of Data Quality}

Trevor Hastie, a professor of Statistics and Biostatistics in Stanford University, pointed out that when you want to seek a significant needle in a pile of data straw, the problem is a large amount of straw looks like the needle [11]. Though the first step of processing accounting data is to gather data, if the workers gather all of data in spite of quality, it is possible to make wrong predictions and decisions. In view of this condition, after gathering data, it is necessary to select relative data and clean conflicting data. 


\subsection{Threat to Privacy}

In 2013, a research report issued by the European Parliament pointed out the big data's threat to privacy in cloud computing era exists, and is more severe than imagination. A professor in University of Toronto said the combination of SNS (Social Networking Services) like Facebook and Twitter and mobile communication technology makes it easy to search individual information in Big Data era. In 2011, a survey conducted by Canada Privacy Commission indicated that 60 percent of the interviewees thought their privacy became more insecure compared with 10 years ago, 55 percent thought the SNS would leak their privacy [12].

\subsection{Lack of Talents}

Big data application requires enterprise to design new data analysis models. That's because traditional models are fit to process structured data not big data including multi-type data. Thus, it needs some data science to apply to enterprise data management. The enterprise is short of talents who can design new data analysis models. The talents who not only can design new data analysis models but also know the financial management are fewer. Lack of talents is a severe and long-term issue.

Big Data is a sword with two blades. Through affecting the idea, function, mode, and method of financial management, it can bring cost saving, risk control, improvement of management efficiency, and increment of value into enterprise. In the meanwhile, it brings a lot of challenges. Only through fostering strengths and circumvent weaknesses, can an enterprise remain invincible in Big Data era.

\section{Acknowledgements}

We are grateful to an anonymous referee for helpful comments. We also wish to thank editorial assistant of Open Journal of Accounting for kind assistance and good suggestions.

\section{References}

[1] Beyer, M.A. and Laney, D. (2012) The Importance of "Big Data”: A Definition. Gartner, G00235055.

[2] http://www.ibm.com/big-data/us/en/index.html

[3] http://www.nsf.gov/funding/pgm_summ.jsp?pims_id=504767

[4] Gerard, G., Martine, H. and Alex, P. (2014) Big Data and Management. Academy of management Journal, 57, 321-326. http://dx.doi.org/10.5465/amj.2014.4002

[5] Ohlhorst, F.J. (2013) Big Data Analytics: Turning Big Data into Big Money. 1st Edition, John Wiley \& Sons, Inc., Indianapolis.

[6] http://www.zdnet.com.cn/wiki-Big Data.

[7] Xu, J.Y. and Xu, L. (2013) Structuring Enterprise of Analyzing Accounting Big Data. Friends of Accounting, 8, 97100.

[8] Lukka, K. (1988) Budgetary Biasing on Organizations: Theoretical Framework and Empirical Evidence. Accounting, Organizations and Society, 13, 281-301. http://dx.doi.org/10.1016/0361-3682(88)90005-0

[9] Feng, Y.F. (2013) IBM: Big Data, Big Finance. Corporate Finance, 7, 62-64.

[10] Dominic, Z. (2010) Keqiangker-Ching: How China’s Next Prime Minister Keeps Tabs on Its Economy. http://www.economist.com/node/17681868

[11] Xu, Z.P. (2012) The Big Data Revolution. 1st Edition, Guangxi Normal University Press, Guangxi.

[12] Zhang, Y.C. (2014) Big Data is a Sword with Two Blades. China Chief Financial Officer, 1, 61. 
Scientific Research Publishing (SCIRP) is one of the largest Open Access journal publishers. It is currently publishing more than 200 open access, online, peer-reviewed journals covering a wide range of academic disciplines. SCIRP serves the worldwide academic communities and contributes to the progress and application of science with its publication.

Other selected journals from SCIRP are listed as below. Submit your manuscript to us via either submit@scirp.org or Online Submission Portal.
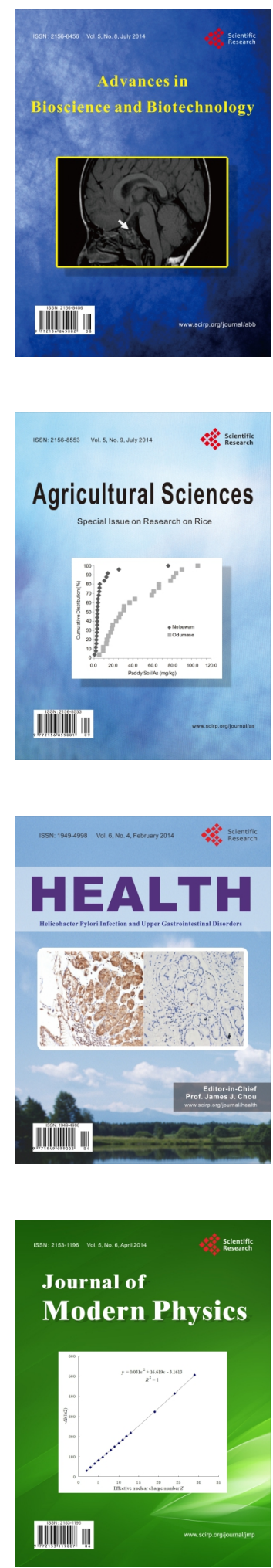
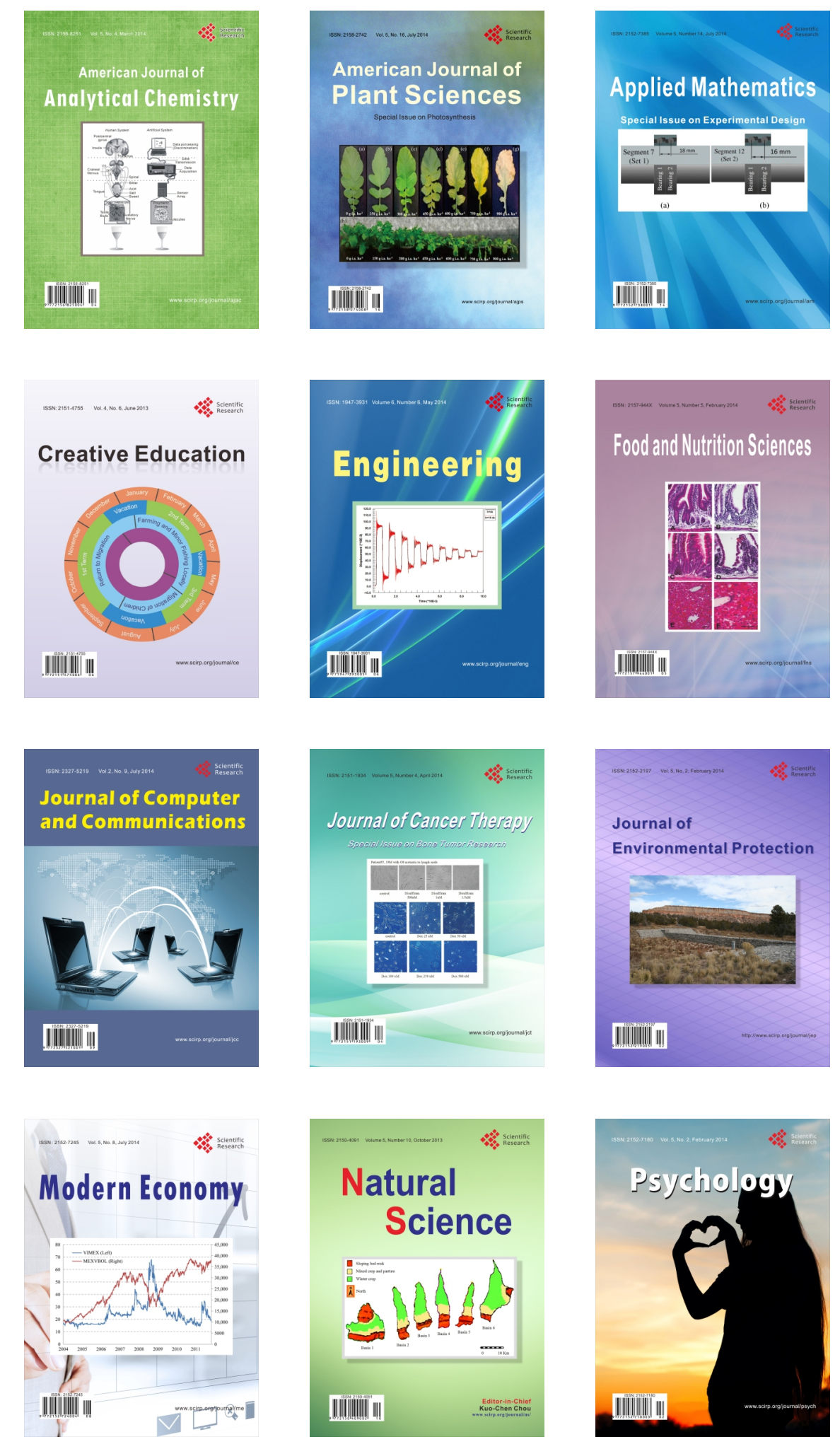